\title{
Synthesis of Carbon Nanocapsules and Nanotubes Using Fe-Doped Fullerene Nanowhiskers
}

\author{
Tokushi Kizuka, ${ }^{1}$ Kun'ichi Miyazawa, ${ }^{2}$ and Daisuke Matsuura ${ }^{1}$ \\ ${ }^{1}$ Institute of Materials Science, Graduate School of Pure and Applied Sciences, University of Tsukuba, Tsukuba, \\ Ibaraki 305-8753, Japan \\ ${ }^{2}$ Fullerene Engineering Group, Advanced Materials Processing Unit, National Institute for Materials Science, Namiki, Tsukuba, \\ Ibaraki 305-0044, Japan \\ Correspondence should be addressed to Tokushi Kizuka, kizuka@ims.tsukuba.ac.jp
}

Received 15 July 2011; Revised 14 October 2011; Accepted 16 October 2011

Academic Editor: Zheng Hu

Copyright (๑) 2012 Tokushi Kizuka et al. This is an open access article distributed under the Creative Commons Attribution License, which permits unrestricted use, distribution, and reproduction in any medium, provided the original work is properly cited.

We synthesized iron-(Fe-)doped $\mathrm{C}_{60}$ nanowhiskers (NWs) by applying the liquid-liquid interfacial precipitation method that employs a $\mathrm{C}_{60}$-saturated toluene solution and a solution of 2-propanol containing ferric nitrate nonahydrate $\left(\mathrm{Fe}\left(\mathrm{NO}_{3}\right)_{3} \cdot 9 \mathrm{H}_{2} \mathrm{O}\right)$. Fe particles of 3-7 nm in diameter were precipitated in the NWs. By heating at $1173 \mathrm{~K}$, the NWs were transformed into hollow and $\mathrm{Fe}_{3} \mathrm{C}$-encapsulated carbon nanocapsules and carbon nanotubes.

\section{Introduction}

Fullerene nanocages, such as carbon nanocapsules (CNCs) and carbon nanotubes (CNTs), can be used to encapsulate functional nanomaterials, leading to potential applications in catalysis and drug delivery [1-13]. Encapsulation of functional nanomaterials has been performed by simultaneous evaporation of metals and diamond by arc discharge $[4,5,8-$ 10]. Chemical vapor deposition, electron irradiation, and thermal decomposition have also been applied to produce CNCs and CNTs [1, 3, 12, 13]. An efficient synthesis method for hollow CNCs using single-crystal fullerene nanowhiskers (NWs) was found by Asaka et al. [14-18]. Fullerene NWs can be synthesized by a simple method, that is, the liquid-liquid interfacial precipitation (LLIP) method [19-23]. In addition, in the LLIP method, fullerene NWs can be doped with metallic particles using $\mathrm{C}_{60}$ derivatives and additives such as metal nitrate nonahydrates in solution [24-26]. Such metallic particles act as catalysts in the syntheses of CNCs and CNTs. In this study, we demonstrate the synthesis of iron-(Fe-) doped $\mathrm{C}_{60}$ NWs using the LLIP method and their application to produce CNCs and CNTs.

\section{Method}

$\mathrm{C}_{60}$ powders were dissolved in toluene to prepare a $\mathrm{C}_{60^{-}}$ saturated solution with a solubility of $2.8 \mathrm{~g} / \mathrm{L}$. In addition, ferric nitrate nonahydrate $\left(\mathrm{Fe}\left(\mathrm{NO}_{3}\right)_{3} \cdot 9 \mathrm{H}_{2} \mathrm{O}\right)$ was dissolved in 2-propanol to give a concentration of $0.1 \mathrm{M}$. Next, the $\mathrm{C}_{60}$ toluene solution was transferred to a glass vial, and the solution of 2-propanol containing $\mathrm{Fe}\left(\mathrm{NO}_{3}\right)_{3} \cdot 9 \mathrm{H}_{2} \mathrm{O}$ was added to form a liquid-liquid interface. The vial was maintained at $278 \mathrm{~K}$ for one week, and the mixed solution was then filtered to extract precipitates. The precipitates were dried and heated under high vacuum at $1173 \mathrm{~K}$ for $1 \mathrm{~h}$. The as-precipitated and heat-treated specimens were dispersed on microgrids and observed by scanning electron microscopy (SEM) and transmission electron microscopy (TEM).

\section{Results}

Figure 1 shows an SEM image of as-precipitated $\mathrm{C}_{60}$ NWs. Figures 2(a) and 2(b) show a bright-field image and a highresolution image of an as-precipitated $\mathrm{C}_{60} \mathrm{NW}$, respectively. The diameters of the as-precipitated NWs ranged from 0.5 to $7.5 \mu \mathrm{m}$, as shown in Figure 3. Lattice fringes with a spacing of 


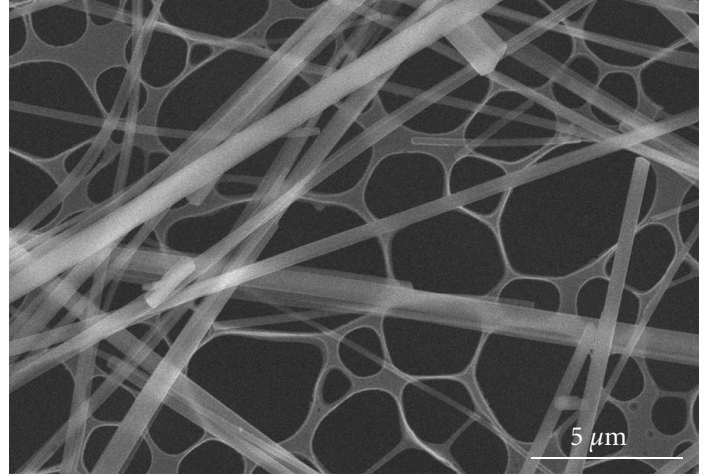

FIGURE 1: Scanning electron microscopy secondary-electron image of as-precipitated Fe-doped $\mathrm{C}_{60}$ nanowhiskers. The nanowhiskers are supported on microgrid.

$0.52 \mathrm{~nm}$ were observed in the NWs, as shown in Figure 2(b). Figure 2(c) shows a selected-area electron diffraction pattern of the NW depicted in Figure 2(a). The high-resolution images and diffraction patterns reveal that the NWs have a tetragonal lattice with lattice constants of $a=0.99 \mathrm{~nm}$ and $c=2.1 \mathrm{~nm}$. The lattice fringes with a spacing of $0.52 \mathrm{~nm}$ depicted in Figure 2(b) correspond to the (004) plane. The long axis of the NW is parallel to the (110) direction. Figure 2(d) shows a high-resolution image of an NW surface, where Fe particles with diameters in the range $3-7 \mathrm{~nm}$ were observed. Thus, the LLIP method using a solution of $\mathrm{Fe}\left(\mathrm{NO}_{3}\right)_{3} \cdot 9 \mathrm{H}_{2} \mathrm{O}$ in 2-propanol resulted in the precipitation of Fe particles in the $\mathrm{C}_{60}$ NWs. Owing to the precipitation of Fe particles, the crystal growth of the NW was inhibited; as a result, the surfaces of the NWs had a rough topography. Therefore, the Fe-doped NWs presented here differ from pure $\mathrm{C}_{60}$ NWs, which are surrounded by plane surfaces [1923].

Figure 4 shows a bright-field image of the heat-treated specimen. Hollow and encapsulating CNCs and CNTs were observed in the specimen, as were chains of CNCs.

Figure 5 shows a bright-field image and a selected-area diffraction pattern of a CNC encapsulating a particle. The 220, $2 \overline{3} 0$, and 050 spots of $\mathrm{Fe}_{3} \mathrm{C}$ (cementite) are observed; the particle was identified to be $\mathrm{Fe}_{3} \mathrm{C}$.

Figures 6(a) and 6(b) show high-resolution images of an $\mathrm{Fe}_{3} \mathrm{C}$-encapsulated CNC. The diameters of the CNCs and the $\mathrm{Fe}_{3} \mathrm{C}$ particles ranged $25-175 \mathrm{~nm}$ and $5-100 \mathrm{~nm}$, respectively, as shown in Figure 7. $\mathrm{The}^{\mathrm{Fe}} \mathrm{C}_{3} \mathrm{C}$ particle does not completely fill the empty space at the core of the CNC. Figure 6(c) shows a high-resolution image of graphene layers in an $\mathrm{Fe}_{3} \mathrm{C}$-encapsulated CNC. The spacing of the graphene layers around the surface is $0.34 \mathrm{~nm}$, whereas the spacing decreases to $0.31 \mathrm{~nm}$ around the graphene/ $\mathrm{Fe}_{3} \mathrm{C}$ interface.

Figure 8(a) shows a high-resolution image of a CNT encapsulating $\mathrm{Fe}_{3} \mathrm{C}$ particles (Figures 8(b) and 8(c)), similar to the case of the CNCs. The $\mathrm{Fe}_{3} \mathrm{C}$ particles encapsulated by the CNTs showed rod shapes, as shown in Figure 8(a). This is different from the spherical $\mathrm{Fe}_{3} \mathrm{C}$ particles observed in CNCs. The diameters of the CNTs and the $\mathrm{Fe}_{3} \mathrm{C}$ particles ranged 10$70 \mathrm{~nm}$ and 5-50 nm, respectively, as shown in Figure 9.

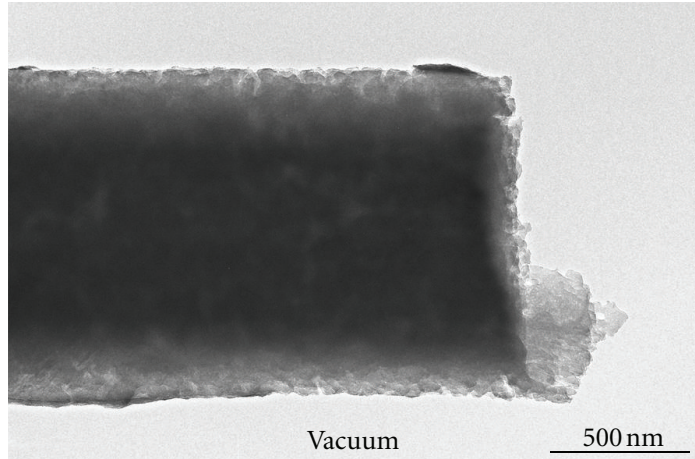

(a)

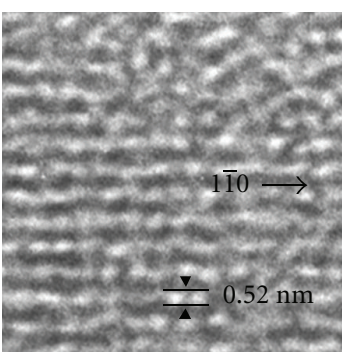

(b)

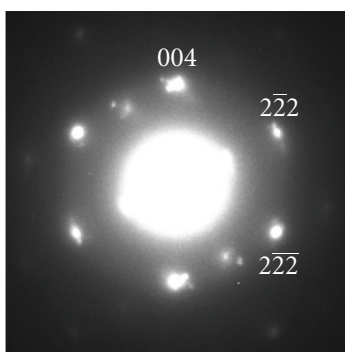

(c)

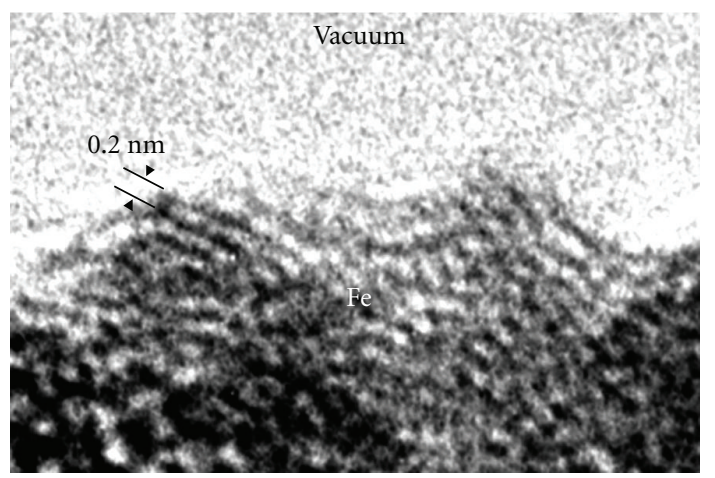

(d)

Figure 2: (a) Bright-field image, (b) high-resolution image, and (c) selected-area electron diffraction pattern of as-precipitated Fedoped $\mathrm{C}_{60}$ nanowhisker. The diameter of the nanowhisker is $1.2 \mu \mathrm{m}$. (d) High-resolution image of Fe particles in the nanowhisker. The lattice fringes of $(110)_{\mathrm{Fe}}$ with a spacing of $0.20 \mathrm{~nm}$ are observed.

The formation of CNCs and CNTs was not confirmed when the heating temperature was changed to $873 \mathrm{~K}, 973 \mathrm{~K}$, $1073 \mathrm{~K}$, and $1123 \mathrm{~K}$. When the heating time was shortened to $0.5 \mathrm{~h}$ at $1173 \mathrm{~K}$, the size distribution of CNCs and CNTs was similar.

\section{Discussion}

4.1. Formation of $\mathrm{Fe}_{3} \mathrm{C}$ Particles. In the as-precipitated NWs, Fe particles 3-7 nm in diameter were observed. On the other hand, after heating at $1173 \mathrm{~K}$, the diameter of the $\mathrm{Fe}_{3} \mathrm{C}$ particles in the CNCs and CNTs was found to increase to 5-100 nm. This implies that the Fe particles had aggregated, and carbon was solved in them during heating. According to Ding et al., pure Fe particles that are several nanometers in 


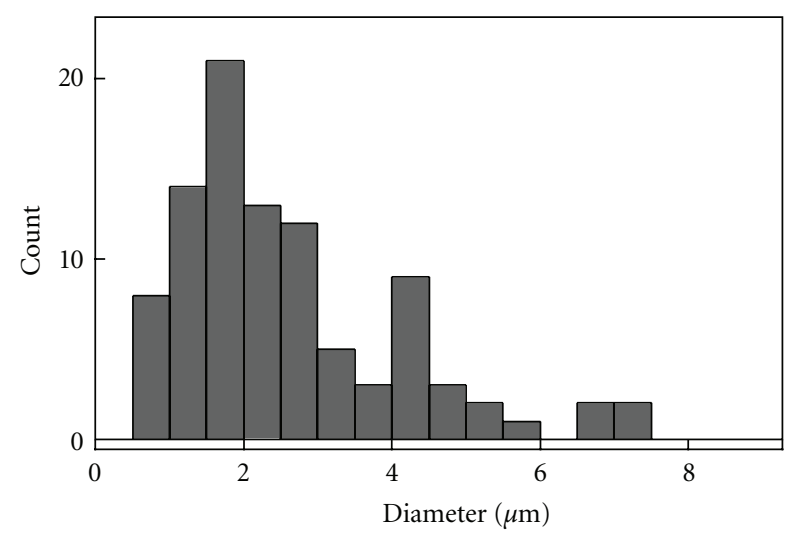

Figure 3: Histogram of diameters of as-precipitated Fe-doped $\mathrm{C}_{60}$ nanowhiskers.

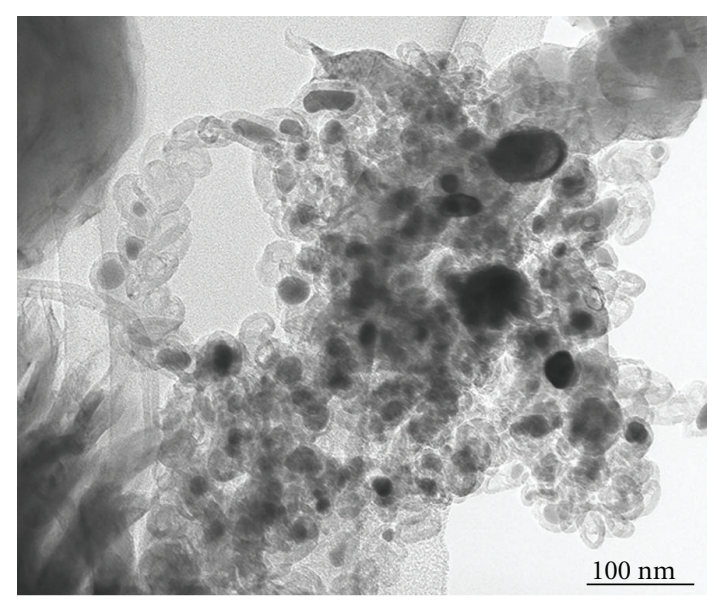

FIGURE 4: Bright-field image of carbon nanocapsules and carbon nanotubes in heat-treated specimen.

size melt at $1000 \mathrm{~K}$ [27]. The melting Fe particles are mobile and fuse together. Fe-carbides with a carbon concentration of more than 50 at $\%$ are formed when the melting Fe particles contact with carbon [28]. During cooling, the solubility limit of carbon in the particles decreases and is followed by the precipitation of graphene layers on the particle surfaces. In this experiment, the particles observed in CNCs and CNTs were $\mathrm{Fe}_{3} \mathrm{C}$. When the carbon concentration of the particles at coagulation exceeds $25 \mathrm{at} \%, \mathrm{Fe}_{3} \mathrm{C}$ particles can be formed in the CNCs and CNTs. Schaper et al. showed from in situ TEM that graphene layers precipitate from $\mathrm{Fe}_{3} \mathrm{C}$ particles at $1143 \mathrm{~K}$ [28]. This temperature is $30 \mathrm{~K}$ lower than the heating temperature used in this study. The $\mathrm{Fe}_{3} \mathrm{C}$ particles shrink owing to the precipitation, resulting in the formation of an empty space at the core of the CNCs [28]. Such empty spaces were observed in this study, as shown in Figure 6(a). $\mathrm{Fe}_{3} \mathrm{C}$ is a quasistable phase and does not transform to other phases at room temperature.

4.2. Formation of CNCs and CNTs. According to Saito, CNCs are produced by the precipitation of carbon from catalysts, that is, metallic or carbide particles [10]. Thus, a CNC encapsulating a particle is initially formed. Jiao et al. showed

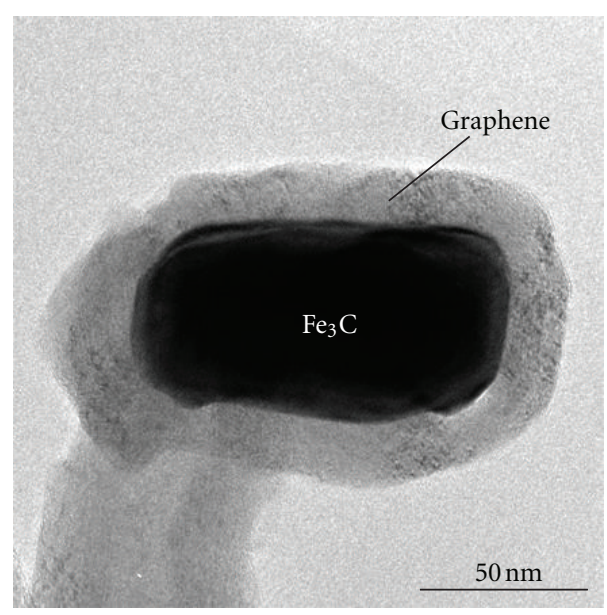

(a)

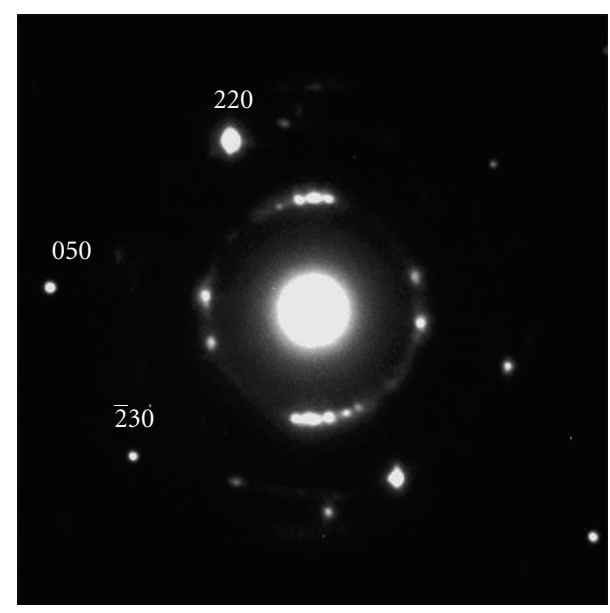

(b)

Figure 5: (a) Bright-field image and (b) selected-area diffraction pattern of $\mathrm{Fe}_{3} \mathrm{C}$-encapsulated carbon nanocapsule. The 220, 230, and 050 spots of $\mathrm{Fe}_{3} \mathrm{C}$ are observed.

from in situ TEM that in, CNCs encapsulating $\mathrm{Fe}$ and $\mathrm{Fe}$ carbide particles, the particle is removed from the CNC at 1173-1373 K [29]. As Ding et al. discussed, the driving force of the particle removal relates to the temperature and concentration gradients in the particle, which are caused by the precipitation of graphene layers [27]. By removal of the particle, the CNC is broken and a hole is formed. This hole is closed by subsequent growth of the layers [30], and hence, a hollow CNC is formed. Subsequently, the next precipitation starts. Thus, the precipitation of graphene layers occurs intermittently. By repeating the processes of precipitation and the removal of the encapsulated particle, hollow CNCs proliferate and one CNC encapsulating the particle remains. The CNCs aggregate, resulting in the formation of a chain, as shown in Figure 4. In the case of the formation of CNTs, the encapsulated $\mathrm{Fe}_{3} \mathrm{C}$ particles showed rod shapes. Tubular graphene layers, that is, CNTs, precipitate around such rodshaped particles. Once a CNT is formed, the encapsulated rod-shaped particle shifts along the symmetric axis of the CNT. Carbon precipitates continuously on the same region of the particle, along one direction, leading to growth of 


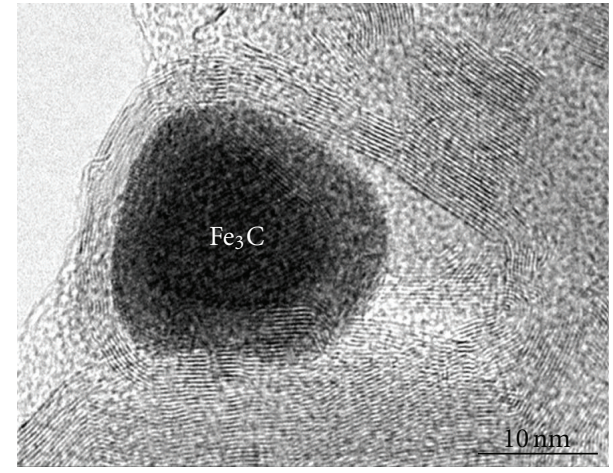

(a)

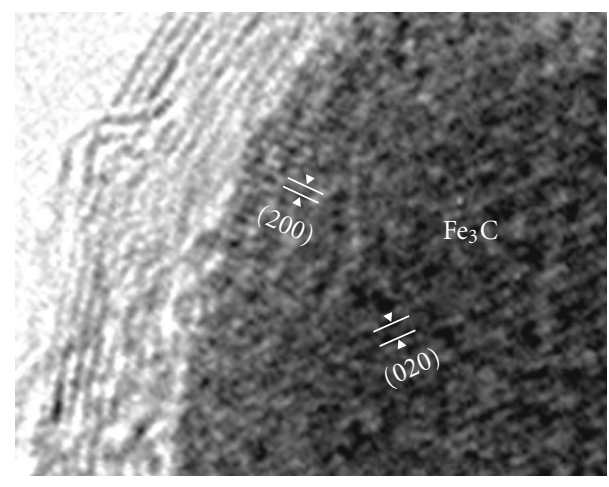

(b)

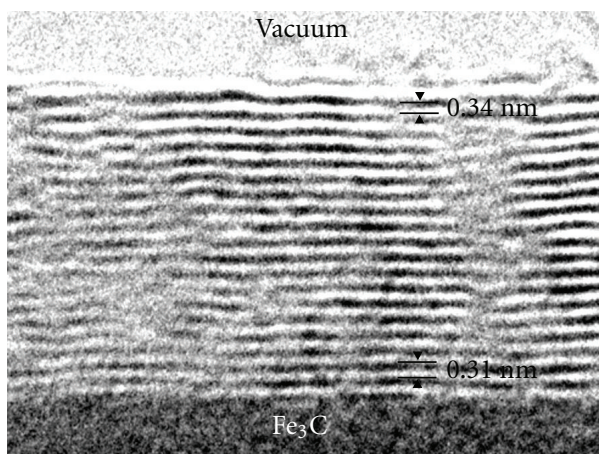

(c)

Figure 6: (a) High-resolution images of $\mathrm{Fe}_{3} \mathrm{C}$-encapsulated carbon nanocapsule and (b) enlargement of the (200) and (020) lattice fringes of the $\mathrm{Fe}_{3} \mathrm{C}$ particle in (a). (c) Graphene layers of the carbon nanocapsule in (a).

the CNT [10]. According to Jourdain et al., a particle is encapsulated in a CNT owing to the strong interfacial tension between the inner wall of the CNT and the surface of the melting particle [31]. It is suggested that the interfacial tension of the rod-shaped particles encapsulated by CNTs is higher than that of the spherical particles in the CNCs. In this study, both CNCs and CNTs were formed in the same specimen. Whether CNCs or CNTs are formed depends on the shape of each encapsulated particle.

4.3. Decrease in the Spacing of Graphene Layers of CNCs. The spacing of the graphene layers decreases to $0.31 \mathrm{~nm}$ around

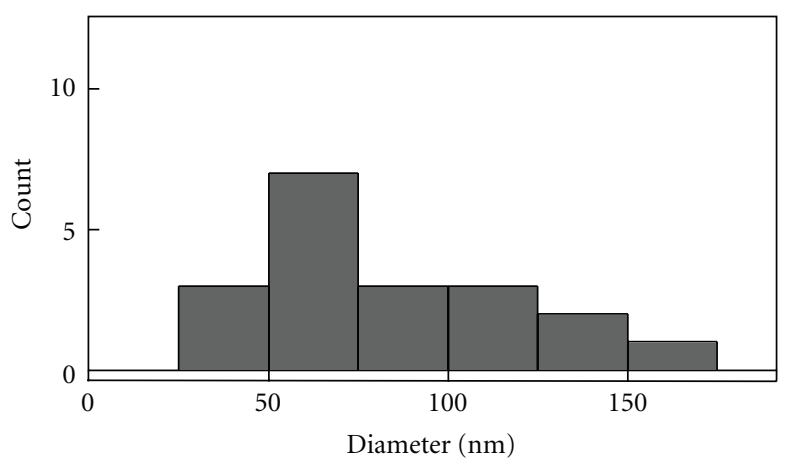

(a) Outer diameter of carbon nanocapsules

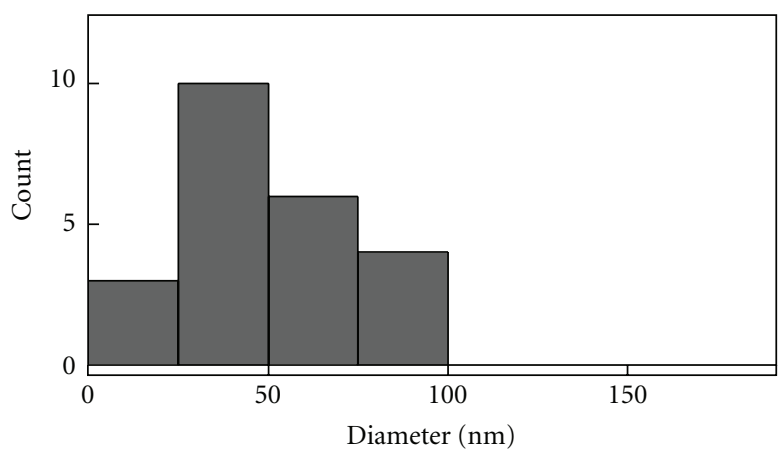

(b) $\mathrm{Fe}_{3} \mathrm{C}$ particles encapsulated by carbon nanocapsules

FIGURE 7: Histograms of (a) outer diameter of carbon nanocapsules and (b) $\mathrm{Fe}_{3} \mathrm{C}$ particles encapsulated by carbon nanocapsules.

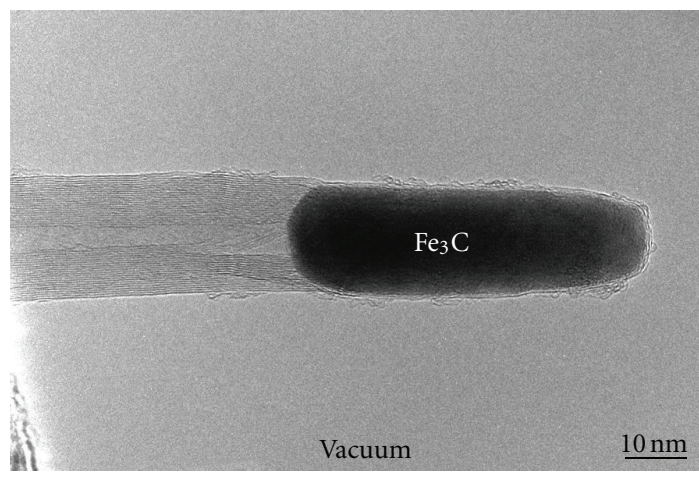

(a)

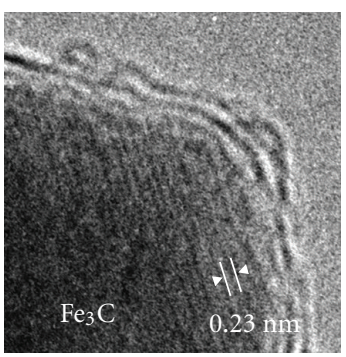

(b)

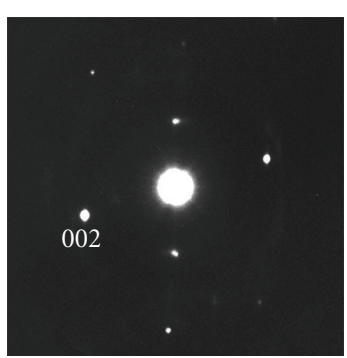

(c)
FIGURE 8: (a) High-resolution image of $\mathrm{Fe}_{3} \mathrm{C}$-encapsulated carbon nanotube. (b) Enlargement of the nanotube tip in (a). (c) Selectedarea electron diffraction pattern of the $\mathrm{Fe}_{3} \mathrm{C}$ particle encapsulated by the nanotube in (a). 


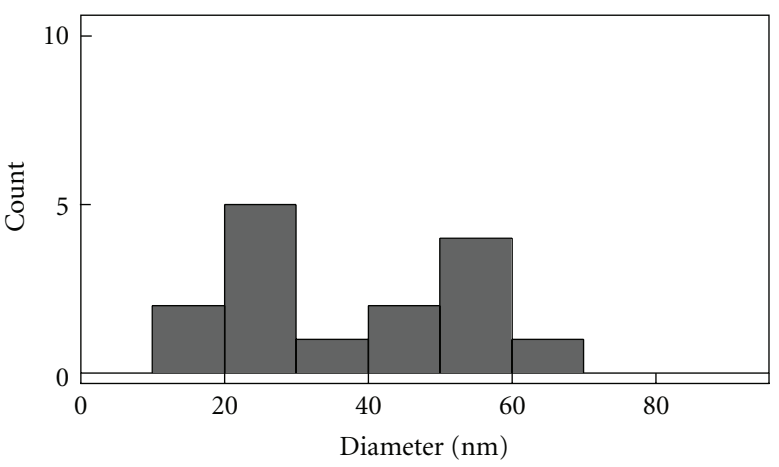

(a) Outer diameter of carbon nanotubes

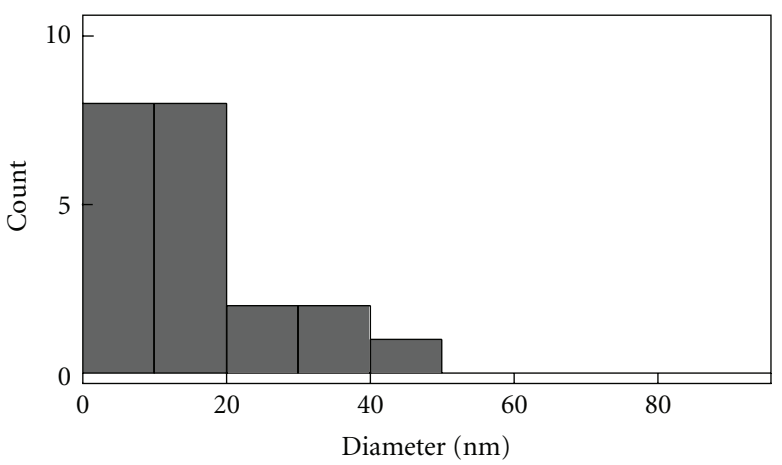

(b) $\mathrm{Fe}_{3} \mathrm{C}$ particles encapsulated by carbon nanotubes

FIGURE 9: Histograms of outer diameter of carbon nanotubes (a) and $\mathrm{Fe}_{3} \mathrm{C}$ particles encapsulated by carbon nanotubes (b).

the graphene/ $\mathrm{Fe}_{3} \mathrm{C}$ interfaces. This spacing is $10 \%$ smaller than that of graphite. Banhart et al. observed a similar reduction in the spacing of graphene layers in carbon onions and interpreted the reduction on the basis of compression and the transition of orbitals from $s p^{2}$ to $s p^{3}[12,13]$. In the $\mathrm{Fe}_{3} \mathrm{C}$-encapsulated CNCs produced in this study, the smaller spacing of the graphene layers is related to the $\mathrm{Fe}_{3} \mathrm{C}$ particle. The bonding between the graphene layers and the $\mathrm{Fe}_{3} \mathrm{C}$ particle may contribute to the transition of orbitals from $s p^{2}$ to $s p^{3}$.

4.4. Characteristics of the Present Method. In this production method of $\mathrm{Fe}_{3} \mathrm{C}$-encapsulated $\mathrm{CNCs}$ and $\mathrm{CNTs}$, Fe-doped FNWs were synthesized by the LLIP method and heating was applied. The LLIP method is performed by a simple process: the mixing of two kinds of liquid around room temperature. Thus, the control of the production is easier than other methods for production of CNCs and CNTs encapsulating particles, for example, arcdischarges [4, 7-9]. In particular, when production quantity becomes larger, the simple control is advantageous although the LLIP process need longer time, for example, one week.

\section{Conclusion}

Fe-doped $\mathrm{C}_{60}$ NWs were synthesized by the LLIP method using a $\mathrm{C}_{60}$-saturated toluene solution and 2-propanol containing $\mathrm{Fe}\left(\mathrm{NO}_{3}\right)_{3} \cdot 9 \mathrm{H}_{2} \mathrm{O}$. The additive of $\mathrm{Fe}\left(\mathrm{NO}_{3}\right)_{3} \cdot 9 \mathrm{H}_{2} \mathrm{O}$ resulted in the precipitation of Fe particles in the $\mathrm{C}_{60} \mathrm{NWs}$.
Heat treatment of the NWs at $1173 \mathrm{~K}$ produced both hollow CNCs and CNTs. Fe ${ }_{3} \mathrm{C}$-encapsulated CNCs and CNTs were also produced. The present method can be applied to synthesize NWs including other metals, for example, cobalt and nickel. Thus, the present method is suitable for the production of CNCs and CNTs encapsulating various foreign nanomaterials.

\section{Acknowledgment}

This study was partly supported by Grants-in-Aid from the Ministry of Education, Culture, Sport, Science, and Technology, Japan (nos. 22310065 and 23651127).

\section{References}

[1] R. D. Heidenreich, W. M. Hess, and L. L. Ban, "A test object and criteria for high resolution electron microscopy," Journal of Applied Crystallography, vol. 1, no. 1, pp. 1-19, 1968.

[2] S. Iijima, "Helical microtubules of graphitic carbon," Nature, vol. 354 , no. 6348 , pp. 56-58, 1991.

[3] D. Ugarte, "Curling and closure of graphitic networks under electron-beam irradiation,” Nature, vol. 359, no. 6397, pp. 707-709, 1992.

[4] R. S. Ruoff, D. C. Lorents, B. Chan, R. Malhotra, and S. Subramoney, "Single crystal metals encapsulated in carbon nanoparticles," Science, vol. 259, no. 5093, pp. 346-348, 1993.

[5] Y. Saito, T. Yoshikawa, M. Inagaki, M. Tomita, and T. Hayashi, "Growth and structure of graphitic tubules and polyhedral particles in arc-discharge," Chemical Physics Letters, vol. 204, no. 3-4, pp. 277-282, 1993.

[6] Y. Saito, T. Yoshikawa, M. Okuda et al., "Carbon nanocapsules encaging metals and carbides," Journal of Physics and Chemistry of Solids, vol. 54, no. 12, pp. 1849-1860, 1993.

[7] Y. Saito, T. Yoshikawa, M. Okuda et al., "Carbon nanocapsules encaging metals and carbides," Journal of Physics and Chemistry of Solids, vol. 54, no. 12, pp. 1849-1860, 1993.

[8] M. Tomita, Y. Saito, and T. Hayashi, " $\mathrm{LaC}_{2}$ encapsulated in graphite nano-particle," Japanese Journal of Applied Physics, vol. 32, no. 2 B, pp. 280-282, 1993.

[9] T. Hihara, H. Onodera, K. Sumiyama et al., "Magnetic properties of iron in nanocapsules," Japanese Journal of Applied Physics, vol. 33, no. 1 A, pp. L24-L25, 1994.

[10] Y. Saito, "Nanoparticles and filled nanocapsules," Carbon, vol. 33, no. 7, pp. 979-988, 1995.

[11] Y. Saito, K. Nishikubo, K. Kawabata, and T. Matsumoto, "Carbon nanocapsules and single-layered nanotubes produced with platinum-group metals ( $\mathrm{Ru}, \mathrm{Rh}, \mathrm{Pd}, \mathrm{Os}, \mathrm{Ir}, \mathrm{Pt})$ by arc discharge," Journal of Applied Physics, vol. 80, no. 5, pp. 30623067, 1996.

[12] F. Banhart, P. Redlich, and P. M. Ajayan, "Irradiation effects in carbon nanostructures," Chemical Physics Letters, vol. 292, no. 4-6, pp. 554-560, 1998.

[13] F. Banhart, "Irradiation effects in carbon nanostructures," Reports on Progress in Physics, vol. 62, no. 8, pp. 1181-1221, 1999.

[14] K. Asaka, R. Kato, Y. Maezono, R. Yoshizaki, K. Miyazawa, and T. Kizuka, "Light-emitting filaments composed of nanometersized carbon hollow capsules," Applied Physics Letters, vol. 88, no. 5, Article ID 051914, pp. 1-3, 2006.

[15] K. Asaka, R. Kato, K. Miyazawa, and T. Kizuka, "Deformation of multiwalled nanometer-sized carbon capsules," Applied Physics Letters, vol. 89, no. 19, Article ID 191914, 2006. 
[16] K. Asaka, R. Kato, R. Yoshizaki, K. Miyazawa, and T. Kizuka, "Conductance of carbon nanocapsule junctions," Physical Review B, vol. 76, no. 11, Article ID 113404, 2007.

[17] T. Kizuka, R. Kato, and K. Miyazawa, "Structure of hollow carbon nanocapsules synthesized by resistive heating," Carbon, vol. 47, no. 1, pp. 138-144, 2009.

[18] T. Kizuka, R. Kato, and K. Miyazawa, "Surface breakdown dynamics of carbon nanocapsules," Nanotechnology, vol. 20, no. 10, Article ID 105205, 2009.

[19] K. Miyazawa, A. Obayashi, and M. Kuwabara, " $\mathrm{C}_{60}$ nanowhiskers in a mixture of lead zirconate titanate Sol- $\mathrm{C}_{60}$ toluene solution," Journal of the American Ceramic Society, vol. 84, no. 3-12, pp. 3037-3039, 2001.

[20] K. Miyazawa, " $\mathrm{C}_{70}$ nanowhiskers fabricated by forming liquid/liquid interfaces in the systems of toluene solution of $\mathrm{C}_{70}$ and isopropy alcohol," Journal of the American Ceramic Society, vol. 85, no. 5, pp. 1297-1299, 2002.

[21] K. Miyazawa, Y. Kuwasaki, A. Obayashi, and M. Kuwabara, " $\mathrm{C}_{60}$ nanowhiskers formed by the liquid-liquid interfacial precipitation method," Journal of Materials Research, vol. 17, no. 1, pp. 83-88, 2002.

[22] K. Miyazawa, K. Hamamoto, S. Nagata, and T. Suga, "Structural investigation of the $\mathrm{C}_{60} / \mathrm{C}_{70}$ whiskers fabricated by forming liquid-liquid interfaces of toluene with dissolved $\mathrm{C}_{60} / \mathrm{C}_{70}$ and isopropyl alcohol," Journal of Materials Research, vol. 18, no. 5, pp. 1096-1103, 2003.

[23] K. Miyazawa, Y. Kuwasaki, K. Hamamoto, S. Nagata, A. Obayashi, and M. Kuwabara, "Structural characterization of $\mathrm{C}_{60}$ nanowhiskers formed by the liquid/liquid interfacial precipitation method," Surface and Interface Analysis, vol. 35, no. 1, pp. 117-120, 2003.

[24] K. Miyazawa, T. Mashino, and T. Suga, "Structural characterization of the $\mathrm{C}_{60}\left[\mathrm{C}\left(\mathrm{COOC}_{2} \mathrm{H}_{5}\right)_{2}\right]$ whiskers prepared by the liquid-liquid interfacial precipitation method," Journal of Materials Research, vol. 18, no. 11, pp. 2730-2735, 2003.

[25] K. Miyazawa and T. Suga, "Transmission electron microscopy investigation of fullerene nanowhiskers and needle-like precipitates formed by using $\mathrm{C}_{60}$ and $\left(\eta^{2}-\mathrm{C}_{60}\right) \mathrm{Pt}\left(\mathrm{PPh}_{3}\right)_{2}$," Journal of Materials Research, vol. 19, no. 8, pp. 2410-2414, 2004.

[26] K. Miyazawa and T. Suga, "Transmission electron microscopy investigation of tubular and capsular needlelike crystals of $\mathrm{C}_{60}$ produced by the liquid-liquid interfacial precipitation method," Journal of Materials Research, vol. 19, no. 11, pp. 3145-3148, 2004.

[27] F. Ding, A. Rosén, and K. Bolton, "The role of the catalytic particle temperature gradient for SWNT growth from small particles," Chemical Physics Letters, vol. 393, no. 4-6, pp. 309313, 2004.

[28] A. K. Schaper, H. Hou, A. Greiner, and F. Phillipp, "The role of iron carbide in multiwalled carbon nanotube growth," Journal of Catalysis, vol. 222, no. 1, pp. 250-254, 2004.

[29] J. Jiao, S. Seraphin, X. Wang, and J. C. Withers, "Preparation and properties of ferromagnetic carbon-coated $\mathrm{Fe}, \mathrm{Co}$, and $\mathrm{Ni}$ nanoparticles," Journal of Applied Physics, vol. 80, no. 1, pp. 103-108, 1996.

[30] D. Ugarte, "How to fill or empty a graphitic onion," Chemical Physics Letters, vol. 209, no. 1-2, pp. 99-103, 1993.

[31] V. Jourdain, H. Kanzow, M. Castignolles, A. Loiseau, and P. Bernier, "Sequential catalytic growth of carbon nanotubes," Chemical Physics Letters, vol. 364, no. 1-2, pp. 27-33, 2002. 

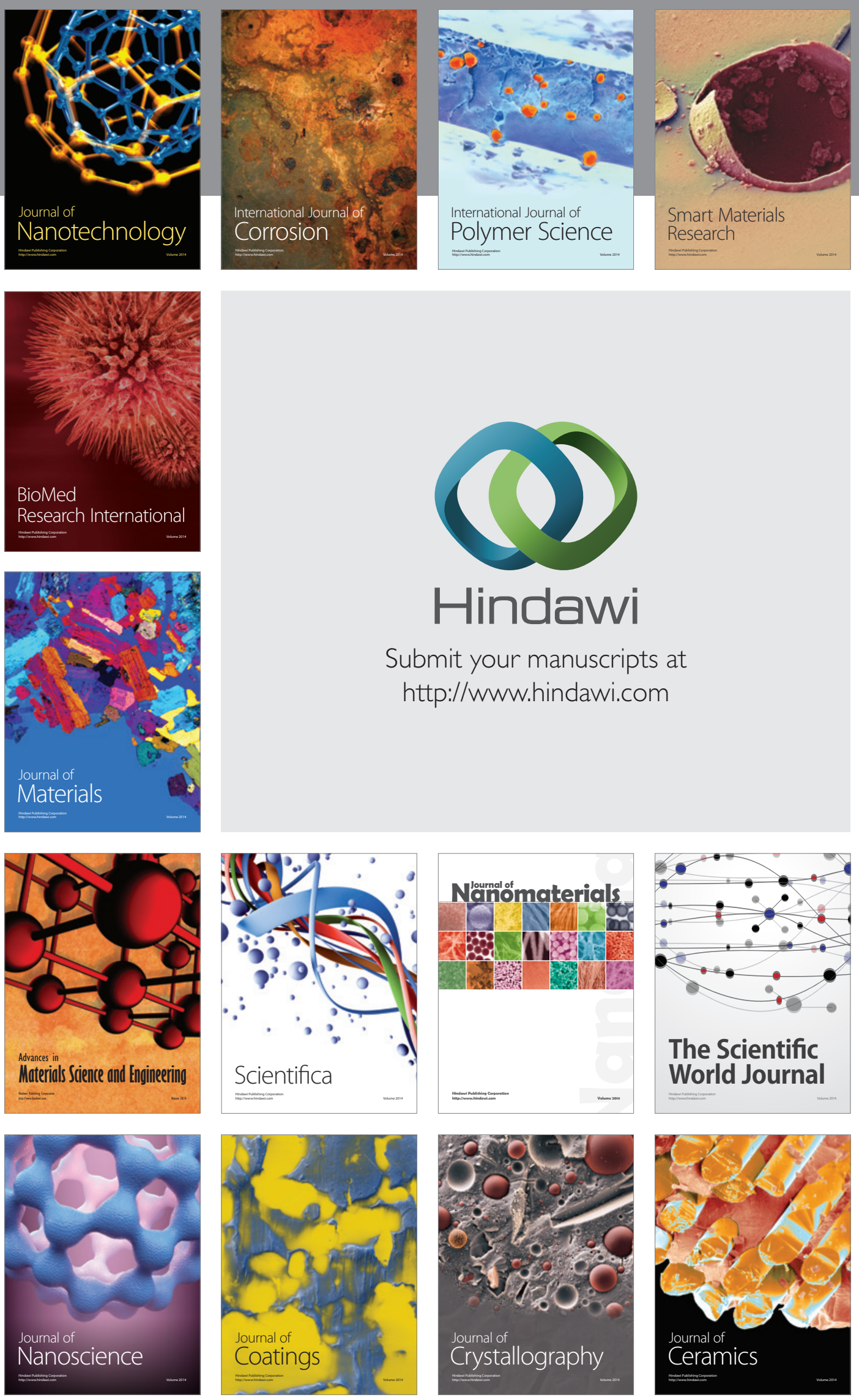

The Scientific World Journal

Submit your manuscripts at

http://www.hindawi.com

\section{World Journal}

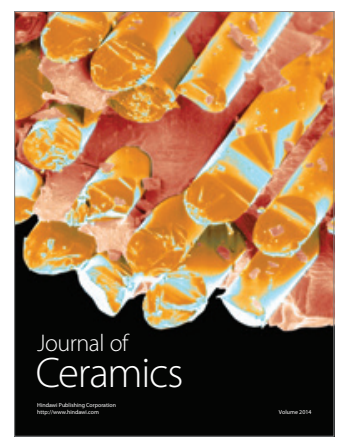

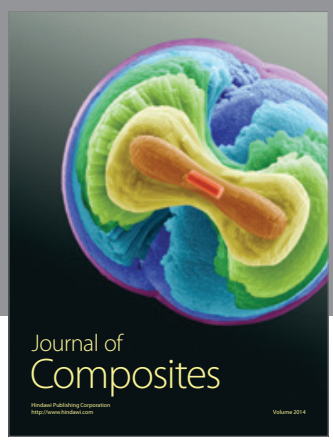
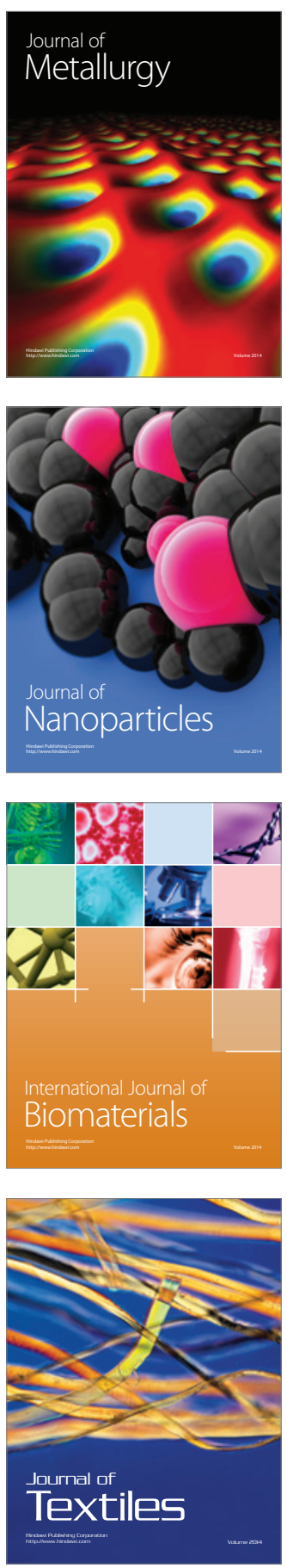